\title{
THE SECRETION OF BILE IN ICTERUS NEONATORUM *
}

\author{
ALFRED F. HESS, M.D. \\ NEW YORK
}

About four years ago I undertook a study of icterus neonatorum by means of the duodenal catheter, ${ }^{3}$ for it seemed as if a method of obtaining bile at the site of entry into the intestine offered advantages over methods hitherto employed. Accordingly a considerable number of infants, some 124 in all, were tested by this means, and observations were made as to the onset of the excretion of bile in the new-born, its relation to the intake of colostrum, and especially as to its association with jaundice. The details of the various cases comprising this investigation will be found in the paper referred to. The results may be broadly summarized in a short table (Table 1 ).

In order to determine the onset of the excretion of bile, tests were carried out day after day for a period of several days on each infant, the aspiration being continued for two ten-minute periods. First, a number of unselected infants were examined, and later a group chosen on account of early or marked icterus. The conclusions drawn from these tests were: that bile is very rarely excreted during the first twelve hours of life; that its secretion in the subsequent days is variable, being more profuse in cases with marked jaundice; that when jaundice manifests itself, it precedes the excretion of bile into the duodenum; that secretion varies within wide limits; and that the occurrence of jaundice results from a defective correlation of excretion and secretion, it being generally caused by the inability of the rudimentary excretion to cope with the sudden profuse secretion of bile.

About a year after the publication of this paper, Ylppö ${ }^{2}$ published a most interesting article on this subject, regarded from an entirely new point of view. He carried out spectrophotometric examinations of the blood, urine and stools in icterus neonatorum, and in this way determined the amount of bile pigments which they contained. His conclusions relating to the occurrence of bile in the stools may be summarized as follows : first, that there is an increased secretion of bile after birth, augmenting gradually during the first five "critical days" until about the sixth day, when there is again a marked rise in the volume of bile secreted; second, that there is no difference between the icteric and the

* Submitted for publication Feb. 4, 1916.

1. Hess, A. F.: Am. Jour. Dis. Child., May, 1912, p. 304.

2. Ylppö, A.: Ztschr. f. Kinderh., 1913, Orig., ix, 208. 
nonicteric infant in the amount of secretion or excretion of bile. Ylppö has represented in the form of curves the gradual rise during the first five days of life, as well as the sudden rise occurring at the end of this period; five curves of this kind are depicted, based on the examinations of eleven infants.

These conclusions-the definite curve of secretion and excretion, as well as the relation of bile excretion to icterus-are, it will be noted, in conflict with the results previously obtained by me, and it is for this reason that $I$ have returned to this subject, especially as this paper has been reviewed in a recent number of this journal. ${ }^{3}$ During the past two years, in view of Ylppö's statements, I have availed myself of numerous opportunities to repeat these tests of the new-born, and have obtained the same results as before and been led to the same conclusions.

Table 1.-Relation of Age to Excretion of Bile (Duodenal Catheter)

\begin{tabular}{|c|c|c|c|c|c|}
\hline $\begin{array}{l}\text { No. of } \\
\text { Cases }\end{array}$ & Age & $\begin{array}{l}\text { No } \\
\text { Bile }\end{array}$ & Bile & Marked & Remarks \\
\hline 52 & $1 / 2$ to 12 hours...... & 51 & 1 & 0 & $\begin{array}{l}\text { Thirty-nine infants were less } \\
\text { than } 6 \text { hours old. }\end{array}$ \\
\hline 19 & 12 to 36 hours...... & 15 & 4 & 4 & $\begin{array}{l}\text { Marked jaundice in all four } \\
\text { positive cases; in others no } \\
\text { bile obtained. }\end{array}$ \\
\hline 15 & $11 / 2$ to 3 days.. & 5 & 10 & 6 & $\begin{array}{l}\text { Marked jaundice in four posi } \\
\text { tive cases; in other two jaun- } \\
\text { diced cases, bile next day. }\end{array}$ \\
\hline 13 & 3 to 4 days......... & 4 & 9 & 6 & Jaundice not increasing. \\
\hline 12 & 4 to 5 days... & 2 & 10 & 5 & Jaundice decreasing. \\
\hline 13 & 6 to 11 days.... & 2 & 11 & 4 & Jaundice decreasing. \\
\hline
\end{tabular}

Before entering into an analysis of the data, in order to attempt to explain the conflicting opinions, we must realize that examinations of the stool furnish merely an indirect method of determining excretion of bile, and that they presuppose something which is by no means certain, namely, that no bile is reabsorbed by the intestine. Tests by means of the duodenal catheter, on the other hand, are not open to this criticism.

At the very outset let me say that I believe $:$ is not possible to construct a reliable curve representing bile excretion in the new-born, and that I relinquished as fruitless such an attempt at the time of writing the previous article. If the degree of secretion were to be depicted graphically, it would not constitute a gradually rising curve, but an irregular and precipitous marking, for the secretion during the first

3. Holmes, J. B.: Am. Jour. Dis. ChILD., January, 1916, p. 62. 
twelve or twenty-four hours is very scant indeed, and generally increases rapidly during the next few days. But graphic illustration is absolutely inapplicable to this study, as in one case there may be an intense secretion of bile by the second day of life, and in others practically none until the fifth or sixth day. Reference to the tests previously reported would seem convincing on this point, for they show all manner of variations in the rate of excretion. How, then, does it come about that Ylppö described a gradually increasing wave of secretion, with a sudden exacerbation about the fifth day? This lay in the very method by which he approached the problem. At the outset he formulated four periods, the first embracing the first five days of life, the second the sixth to the eighth day, the third from the ninth to the eleventh day, and the fourth the twelfth and thirteenth days. As he found a decidedly greater amount of bile in the stool passed during the second period, which, we will remember, began with the fifth day, than that passed during the first period, he drew the conclusion that a sudden flow of bile occurred on about this day, and outlined a hypothetical curve to represent a gradually increasing secretion throughout the first period. It is evidently impossible, as has been pointed out elsewhere, ${ }^{4}$ to construct a curve of daily excretion by determining the bile in the total stool passed during these several periods, or to form any opinion whatsoever as to the degree of secretion or excretion for the individual twenty-four periods during the first five days of life. Nor is it possible to state that there is a sudden rise taking place at the fifth or sixth day. This method evidently allows one merely to compare the four periods one with another. Daily tests carried out by means of the duodenal catheter, however, have led me to the opinion that there is an initial lack of excretion during the first twenty-four hours or more, and that there follows a somewhat sudden rise in the outflow of bile, this increase taking place generally before the fifth day, frequently on the third or fourth day.

The second question for consideration is whether there is an increased excretion of bile more often in infants showing decided icterus than among those who manifest no signs of jaundice. Ylppö answers this in the negative. His conclusions are based on a study of ten cases, in which the amount of bile pigment was determined in the total stool passed during the first five days. The data of these cases are given in Table 2 and show the grade of icterus, the total amount of bile pigment found, and the total number of grams of stool excreted. It would seem as if ten cases were very few on which to base definite conclusions, especially when these cases must be subdivided so as to represent three clinical groups, one showing no jaundice, another moderate jaundice,

4. Hess, A. F.: Ergeb. d. inn. Med. u. Kinderh., 1914, xiii, 560. 
and a third marked or intense jaundice. Furthermore, it will be noted in the table that in two of the three cases in which no jaundice occurred, but in which, nevertheless, a marked excretion of bile took place, the amount of stool obtained during this period was exceptionally large, indeed, two or three times the number of grams collected in many of the other cases. This is difficult to understand, and certainly renders these cases unsuitable for the purpose of comparison, for we should expect to obtain an abnormal amount of bile under such circumstances.

TABle 2.-Relation of Bile Excretion to Stool Passed During First Five Days of Life, (Ylppö's Cases.)

\begin{tabular}{|c|c|c|c|c|}
\hline $\begin{array}{l}\text { Case } \\
\text { No. }\end{array}$ & $\begin{array}{l}\text { Grade of } \\
\text { Icterus }\end{array}$ & $\begin{array}{c}\text { Total Bile } \\
\text { in Stool } \\
\text { in First } \\
\text { Five Days, } \\
\text { Mg. }\end{array}$ & $\begin{array}{c}\text { Total } \\
\text { Stool, } \\
\text { Gm. }\end{array}$ & Remarks \\
\hline 1 & Negative & 28.16 & 16.09 & \multirow{10}{*}{$\begin{array}{l}\text { Immerse quantity of bile pigment ex- } \\
\text { (reted in next two days }(57.83 \mathrm{gm} \text {. })\end{array}$} \\
\hline$\underline{2}$ & Marked & 8.28 & 3.22 & \\
\hline 3 & Moderate & 39.79 & 4.72 & \\
\hline 4 & Moderate & 21.13 & 2.93 & \\
\hline 5 & Negative & 43.89 & 5.72 & \\
\hline 6 & Moderate & $29.9 \bar{o}$ & 9.63 & \\
\hline 7 & Negative & 32.77 & 13.42 & \\
\hline 8 & Very marked & 21.70 & 12.35 & \\
\hline 9 & Slight & 33.85 & 6.50 & \\
\hline 10 & Marked & 28.84 & 19.10 & \\
\hline
\end{tabular}

It is quite true that there is no absolute parallelism between bile excretion and jaundice. Cases previously reported illustrate the occasional occurrence of a wide divergence in these respects. For example, we have noted a high degree of jaundice accompanied by an excessive secretion of bile; no secretion of bile, and almost an absence of jaundice during the first five days of life; and an instance showing marked jaundice on the fourth day, but no secretion of bile until two days later. These cases, however, constitute the exceptions. If we examine a hundred or more cases, more particularly if we select a number of infants on account of the occurrence of marked jaundice, we shall find that an excessive excretion of bile is associated more often with a marked than with a faint degree of jaundice. This will be more especially the case if the duodenal tests are carried out between the second and fifth day, when the excretion has been well established and the icterus has begun to recede. ${ }^{5}$

5. It is difficult to conceive how it will be possible to estimate the daily excretion of bile during life by any method other than duodenal tests. The only other possible means of access would seem to be a fistula. 
The amount of bile flow and the icterus do not depend on one factor, but on two-secretion and excretion. This is well illustrated by some cases of congenital obliteration of the bile ducts described by Still ${ }^{6}$ and also by Thompson, ${ }^{7}$ in which, in spite of the absolute obstruction, there was no jaundice for some weeks owing to the lack of secretion. When jaundice is intense, however, the secretion of bile cannot be wanting, and we are more apt to encounter it in plenty in the duodenum than to find it deficient. In cases selected on account of marked jaundice, bile was frequently found in the stomach by means of a stomach tube, or appeared with regurgitated colostrum, owing to the fact that its marked alkalinity tended to a relaxation of the pyloric sphincter. In the most marked case which we met with, in which the infant assumed a saffron color, there was an almost constant welling forth of bile into the stomach.

\section{CONCLUSIONS}

In conclusion we may state that the amount of bile-flow during the first twelve to thirty-six hours of life is very scanty, and that, although it then increases in volume, it is subject to wide fluctuations. It is therefore inaccurate to depict it graphically, as has been attempted, as a gradual rise dating from the time of birth. To quote from our previous paper: "The secretion of bile varies within wide limits. In general it is marked when jaundice is marked."

Furthermore, recent investigations of icterus neonatorum seem to confirm the interpretation that "the occurrence of jaundice results from a defective correlation of excretion and secretion, and is generally caused by the inability of the rudimentary excretion to cope with the sudden profuse secretion of bile."

16 West Eighty-Sixth Street.

6. Still, G. F.: Clin. Jour., 1901, xvii, 323.

7. Thompson, J.: Congenital Obliteration of the Bile Ducts, 1902. 